\title{
Analytical Evaluation of Reinforced Concrete Pier and Cast-in-Steel-Shell Pile Connection Behavior considering Steel-Concrete Interface
}

\author{
Jiho Moon, ${ }^{1}$ Dawn E. Lehman, ${ }^{2}$ Charles W. Roeder, ${ }^{2}$ Hak-Eun Lee, ${ }^{3}$ and Tae-Hyung Lee ${ }^{4}$ \\ ${ }^{1}$ New Transportation Research Center, Korea Railroad Research Institute (KRRI), Uiwang-si, Gyeonggi-do 16105, Republic of Korea \\ ${ }^{2}$ Department of Civil \& Environmental Engineering, University of Washington, Seattle, WA 98195, USA \\ ${ }^{3}$ Department of Architectural, Civil \& Environmental Engineering, Korea University, Seoul 02841, Republic of Korea \\ ${ }^{4}$ Department of Civil Engineering, Konkuk University, Seoul 05029, Republic of Korea \\ Correspondence should be addressed to Tae-Hyung Lee; thlee@konkuk.ac.kr
}

Received 25 August 2015; Revised 25 December 2015; Accepted 27 December 2015

Academic Editor: Kaveh Edalati

Copyright (C) 2016 Jiho Moon et al. This is an open access article distributed under the Creative Commons Attribution License, which permits unrestricted use, distribution, and reproduction in any medium, provided the original work is properly cited.

\begin{abstract}
The seismic design of bridges may require a large-diameter deep pile foundation such as a cast-in-steel-shell (CISS) pile where a reinforced concrete $(\mathrm{RC})$ member is cast in a steel casing. In practice, the steel casing is not considered in the structural design and the pile is assumed to be an RC member. It is partially attributed to the difficulties in evaluation of composite action of a CISS pile. However, by considering benefits provided by composite action of the infilled concrete and the steel casing, both the cost and size of CISS pile can be reduced. In this study, the structural behavior of the RC pier and the CISS pile connection is simulated by using an advanced 3D finite element (FE) method, where the interface between the steel and concrete is also modeled. Firstly, the FE model is verified. Then, the parametric study is conducted. The analysis results suggest that the embedment length and the friction coefficient between the steel casing and the infilled concrete affect the structural behavior of the RC pier. Finally, the minimum embedment length with reference to the AASHTO design guideline is suggested considering the composite action of the CISS pile.
\end{abstract}

\section{Introduction}

Cast-in-steel-shell (CISS) piles are driven pipe piles filled with cast-in-place reinforced concrete (RC) with longitudinal and transverse reinforcing bars. CISS piles are frequently used for a bridge foundation when the construction site consists of soft or liquefiable soil or when a large lateral soil deformation due to seismic loading is expected. The construction sequences of a CISS pile are as follows: (1) a steel casing is driven, (2) soil inside the steel casing is removed, (3) a mesh of longitudinal and transverse reinforcing bars is placed, and (4) the concrete is poured and cured. These elements can exceed $2 \mathrm{~m}$ in diameter and more than $70 \mathrm{~m}$ in length. An example of the CISS pile is Pier No. 4 of the Ebey Slough project in Washington State as shown in Figure 1. In this case, the steel casing is $1.8 \mathrm{~m}$ in diameter and $25 \mathrm{~mm}$ thick. The CISS pile extends approximately $72.5 \mathrm{~m}$ below the base of the bridge pier. The CISS pile is reinforced with $32 \# 14$ longitudinal bars (the diameter of \#14 reinforcing bar is $43 \mathrm{~mm}$ ) and heavy spiral transverse reinforcement.

A CISS pile is typically designed as an RC member ignoring the strength of the steel casing and the composite action between the steel casing and the infilled concrete [1]. The current AASHTO LRFD bridge design specification [2] provides the design details of such piles but does not consider the strength of the steel casing. There are a few reasons for ignoring the strength of the steel casing in the CISS pile design. Firstly, the composite action of the steel casing and the infilled concrete is unclear since the friction coefficient may decrease with increasing the dirt or other debris in the steel casing. Secondly, the steel casing is not properly protected from rusting and it may lead to the reduction of the steel crosssectional area. Thirdly, the steel casing may be damaged during the drilling process which also leads to the reduction of the steel cross-sectional area. These problems might be solved by using the weathering steel to prevent the corrosion 


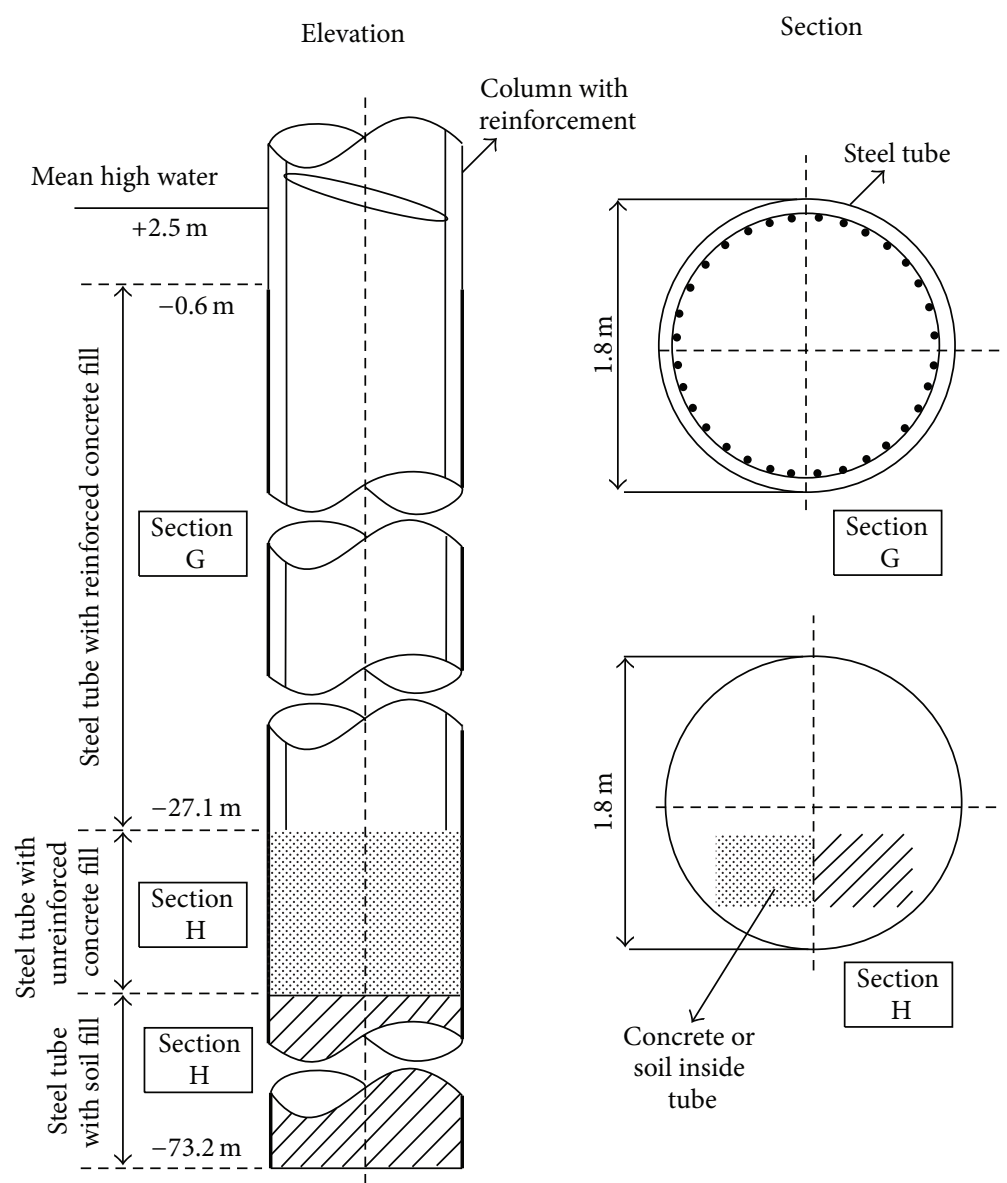

Figure 1: Pier No. 4 Caisson Ebey Slough.

or high ductility steel to reduce the damage of the tube during the drilling process. In such case, the contribution of the steel tube to the structural behavior of the CISS pile can be considered for the design of such pile.

Roeder and Lehman [1] show the significant benefits of employing the strength provided by the steel casing in addition to the infilled concrete for the design of a CISS pile. They suggest that the CISS pile can be designed as a concrete filled tube (CFT) member. One of the most crucial advantages of such a design approach is that the reinforcement inside the CISS pile can be removed as the steel casing replaces the reinforcing bars. This will reduce the cost of the CISS pile and the construction process becomes simpler. If this is the case, the longitudinal reinforcement of the RC pier needs to be embedded into the infilled concrete of the CISS pile so that the strength of the reinforcement is fully developed. Therefore, it is important to understand the proper embedment length of the longitudinal reinforcement considering the interface behavior between the infilled concrete and the steel casing in the CISS pile. However, most of the studies about CISS pile are focused on the mechanical behavior of CISS pile itself and connection behavior of the CISS pile is limited [3-5].

The objective of this study is to investigate the behavior of the RC pier and the CISS pile connection considering the interface between the steel casing and the infilled concrete.
For this, the finite element (FE) model to simulate the RC pier and the CISS pile connection is developed where the interface characteristic between the steel and concrete is also modeled. Then, a series of FE analysis is conducted for a parametric study. In particular, the embedment length of the longitudinal reinforcement in the RC pier to the CISS pile (referred to as the embedment length for short) is selected as a key parameter. The friction characteristic between the steel casing and the infilled concrete is also an important parameter and its effect on the connection behavior is studied. Finally, the minimum embedment length is proposed based on the results of parametric study.

\section{Description and Verification of FE Analysis Model}

As mentioned in the introduction, the lack of validated design models for the connection limits the use of the CISS pile. There are several important aspects of the design of the CISS pile-to-RC pier connection. The first is the required embedment length for the full function of the RC pier. In addition, other parameters including the relative CISS pileto-RC pier diameter and axial load ratio can influence the response. Here, the objective is to conduct a parametric study of the salient variables. As pointed out previously, the 


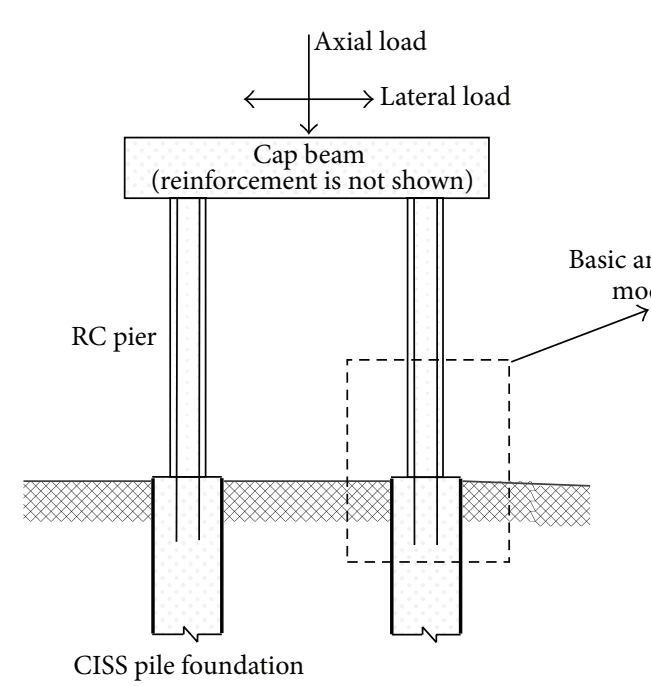

(a)

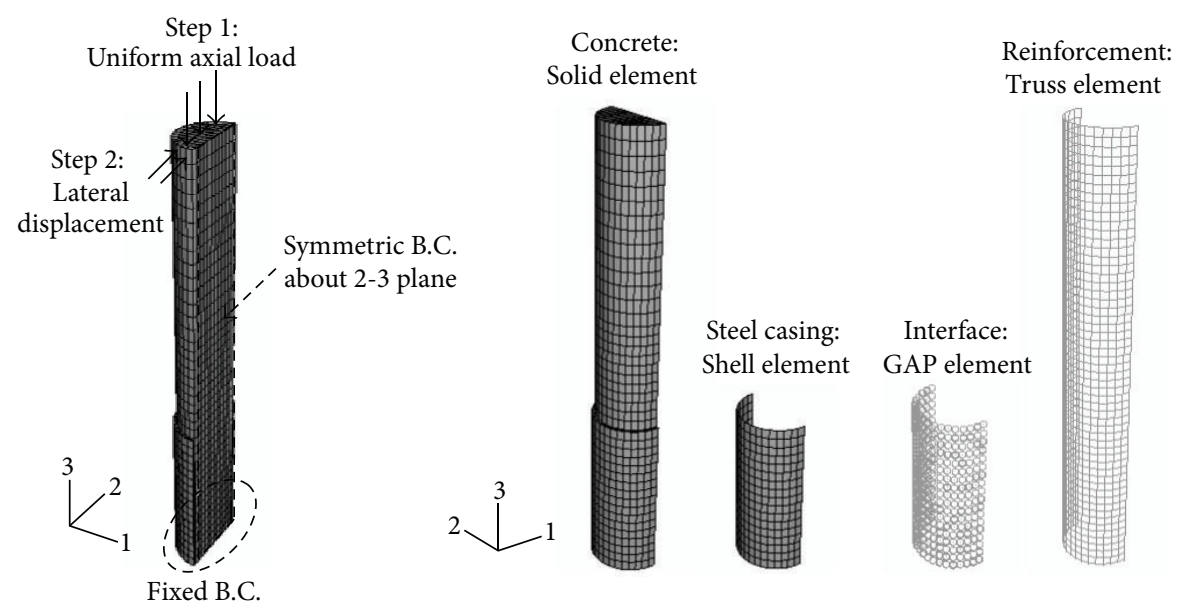

FIgURE 3: Boundary condition, loading, and element used in the finite element model.

study about the CISS pile-to-RC pier connection is limited. Therefore, a validated FE modeling approach is developed to study this connection. The nonlinear FE analysis is performed by using general purpose FE analysis package ABAQUS [7]. First, the model is validated using prior experimental results on the concrete filled tube (CFT) components and $\mathrm{RC}$ components subject to combined loading. The validated model is used to conduct a parametric study, which is then used to evaluate design expression for this connection.

2.1. Description of FE Analysis Model. The typical CISS pileto-RC pier connection is illustrated in Figure 2 where $D_{1}$ and $D_{2}$ are the diameters and $L_{1}$ and $L_{2}$ are the lengths of the RC pier and CISS pile, respectively, and $l_{e}$ is the embedment length. $P$ and $H$ are the axial and the lateral forces that act on the RC pier. Figure 3 shows the FE model of the CISS pile-to$\mathrm{RC}$ pier connection used in this study. For efficient modeling, only half of the system is modeled by taking advantage of the symmetry. This approach can reduce the computational time. The infilled concrete is modeled using 8-node solid elements with reduced integration point and the steel casing is modeled using 4-node shell elements with reduced integration point. At each nodal point, GAP elements are used to simulate the interface between the infilled concrete and the steel casing. The GAP element allows for two nodes to be in contact (gap closed) or separated (gap open) with respect to a particular direction and a separation condition [7]. Thus, infinite stiffness in compression and no stiffness in tension condition can be simulated by using the GAP element. This modeling approach provides three distinct advantages. Firstly, the relative movement (slip) between the steel casing and the infilled concrete can be modeled directly. Secondly, the GAP element can simulate Poisson's effect of the concrete in compression, providing confinement stress 
to infilled concrete. Therefore, confining effects are modeled directly and an empirical model of the compressive stressstrain relationship of the confined concrete is not necessary [8]. Thirdly, shear stresses between the steel casing and infilled concrete are modeled by friction, which is specified by a friction coefficient defined in GAP elements. The truss elements are used to model the reinforcing bars, where the truss element has 2 nodes with axial displacement degree of freedom and 1 integration point at the center, and they are embedded into the concrete by using EMBEDED option in ABAQUS [7]. This modeling approach to the CISS pile is previously verified by comparing with experimental results under various loading and boundary conditions $[8,9]$.

Analysis of the CISS pile includes many nonlinear responses such as concrete cracking and contact problems. Thus, to ensure the convergence of the solution, STABILIZE option in ABAQUS [7] is used in this study. STABILIZE option provides an automatic mechanism for stabilizing unstable quasi-static problems through the automatic addition of volume-proportional damping to the model [7].

The bottom of the analysis model is fixed against rotation and translation, as shown in Figure 3. The translation in direction 1 is restrained for the middle plane to simulate the symmetric boundary about 2-3 plane, as shown in Figure 3. A vertical pressure is applied at the top of the model to simulate the axial load in the first loading step. Then, a monotonically increasing lateral load is applied using a displacement control option, as shown in Figure 3.

As mentioned earlier, a CISS pile can exceed more than $70 \mathrm{~m}$ in length. Thus, the length of the CISS pile simulated in the analytical model should be appropriately selected to ensure efficiency and accuracy. In this study, the optimal length of the CISS pile is selected such that it is long enough to minimize the end effect due to the boundary condition while it is short enough to minimize the number of degrees of freedom of the model. The selected length of the FE model of the CISS pile is twice the diameter of the CISS pile according to a parametric study.

Figure 4 shows the material models used in this study. The uniaxial compressive and tensile behaviors of the plain concrete are modeled using the expressions proposed by Saenz [10] and Hsu and Mo [11], respectively, as shown in Figure 4(a), where Young's modulus of the concrete, $E_{c}$, is estimated as $4,700 \sqrt{ } f_{c}^{\prime}(\mathrm{MPa})$ according to ACI design code [12]. $\varepsilon_{c}^{\prime}$ in Figure 4(a) is set as 0.003. $f_{c r}$ of the concrete is defined as $0.31 \sqrt{ } f_{c}^{\prime}(\mathrm{MPa})$ based on the results of Hsu and Mo [11]. The elastic response is assumed up to $0.5 f_{c}^{\prime}$. To simulate inelastic behavior of the concrete under a general 3D stress state, the concrete damaged plasticity model in ABAQUS [7] is adopted. A value of $20^{\circ}$ for the dilation angle, $\psi$, is adopted from the previous research for the CFT modeling conducted by Moon et al. [8], and $31^{\circ}$ for the RC pier is determined from the comparison with the previous RC column test conducted by Pang et al. [13].

The average stress-strain relationship of a reinforcing bar embedded in concrete is different from that of a bare reinforcing bar [11]. The primary difference is the lower effective yield stress of reinforcing bar, $f_{y r}$. In this study, the average stress-strain relationship of an embedded reinforcing bar proposed by Hsu and Mo [11] is adopted, as shown in Figure 4(b). Young's modulus of the reinforcing bar, $E_{r}$, is assumed to be $200 \mathrm{GPa}$. In Figure $4, f_{y r}^{\prime}$ (the reduced effective yield stress of the reinforcing bar) and $E_{p r}^{\prime}$ are the function of the reinforcement ratio, $\rho$, and the details of calculation of these values can be found in [11].

For the steel casing, a trilinear stress-strain relationship is used with an isotropic hardening plasticity rule. Young's modulus of the steel, $E_{s}$, is approximated to $200 \mathrm{GPa}$, and Poisson's ratio of the steel, $v_{s}$, is set as 0.3 . The plastic plateau terminates when strain of the steel, $\varepsilon_{s}$, is equal to 10 times the yield strain of the steel $\left(10 \varepsilon_{s y}\right)$ and stress increases up to ultimate strength of the steel, $f_{u}$, which is achieved when the ultimate strain of the steel, $\varepsilon_{s u}$, is 0.1, as shown in Figure 4(c).

2.2. Verification of FE Analysis Model. The test results from Low and Moehle [6] are used to verify the accuracy of the model for well and poorly embedded reinforcement. Figure 5(a) shows the dimensions of the test specimen where the column section is $127 \mathrm{~mm}$ by $165 \mathrm{~mm}$ and the longitudinal reinforcement consisted of $\# 2$ and $\# 3$ bars. (The diameters of \#2 and \#3 bars are $6.35 \mathrm{~mm}$ and $9.525 \mathrm{~mm}$, resp.) The reinforcing bars are embedded to a depth of $117.8 \mathrm{~mm}$, as shown in Figure 5(a). In addition to the experimental results, analytical results by Luccioni et al. [14] are used for verification. Luccioni et al. [14] conduct a structural analysis for the model shown in Figure 5(a) to verify their bond-slip model for reinforcing bar. Then, they conduct a parametric study to investigate the effect of the embedment length of the longitudinal reinforcing bar. Both the analytical results of Luccioni et al. [14] and the experimental results from Low and Moehle [6] are used to validate the FE model developed in this study.

Figure 5(b) shows the column-foundation designs studied in Luccioni's study. The models have embedment lengths of approximately $19 d_{b 3}(177.8 \mathrm{~mm}), 8 d_{b 3}(76.2 \mathrm{~mm})$, and $3 d_{b 3}$ $(25.4 \mathrm{~mm})$ where $d_{b 3}$ is the diameter of a \#3 bar. The results of Low and Moehle [6], Luccioni et al. [14], and the proposed model in this study are compared in Figure 6(a). The stiffness and peak strength are very similar for all three models. For the shorter embedment lengths $\left(l_{e}=76.2\right.$ and $\left.25.4 \mathrm{~mm}\right)$, as shown in Figures 6(b) and 6(c), postpeak behaviors of the two simulated analyses are slightly different. However, neither has been verified with experimental results and slight differences are expected with different approaches for the interface modeling between reinforcing bar and concrete. For the comparison of the peak strength, the difference between the analysis models and the results of Luccioni et al. [14] are 5\% and $1 \%$ for the models having the embedment length of $8 d_{b 3}$ and $3 d_{b 3}$, respectively. Thus, the proposed FE model is appropriate to simulate the behavior of the CISS pile-to-RC pier connection.

\section{Parametric Study}

3.1. Models for Parametric Study. A parametric study is performed to evaluate the effect of salient design parameters 


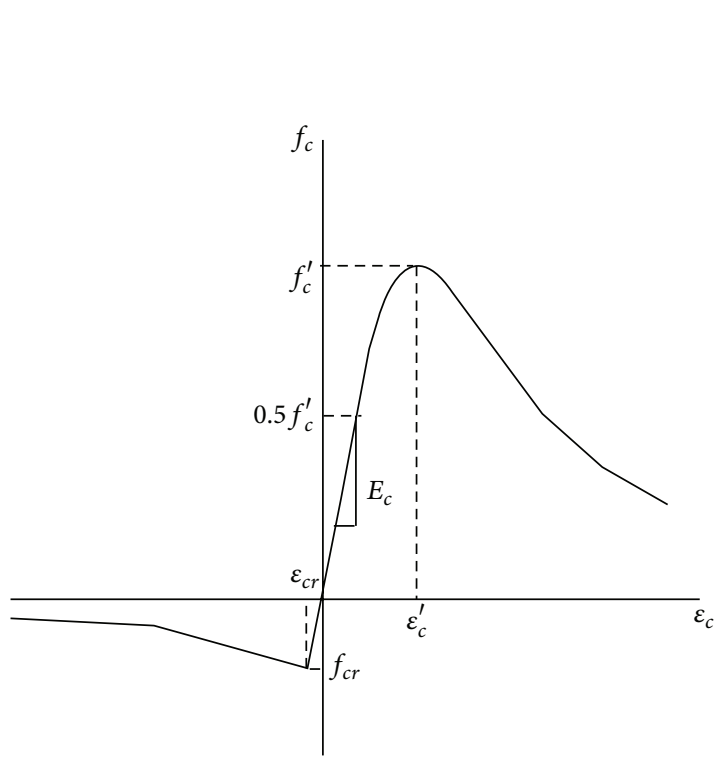

(a)

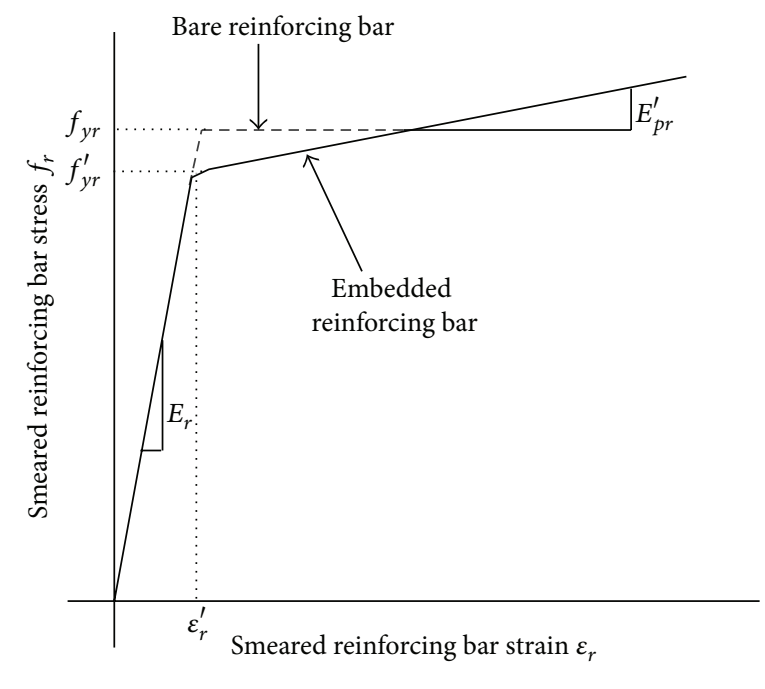

(b)

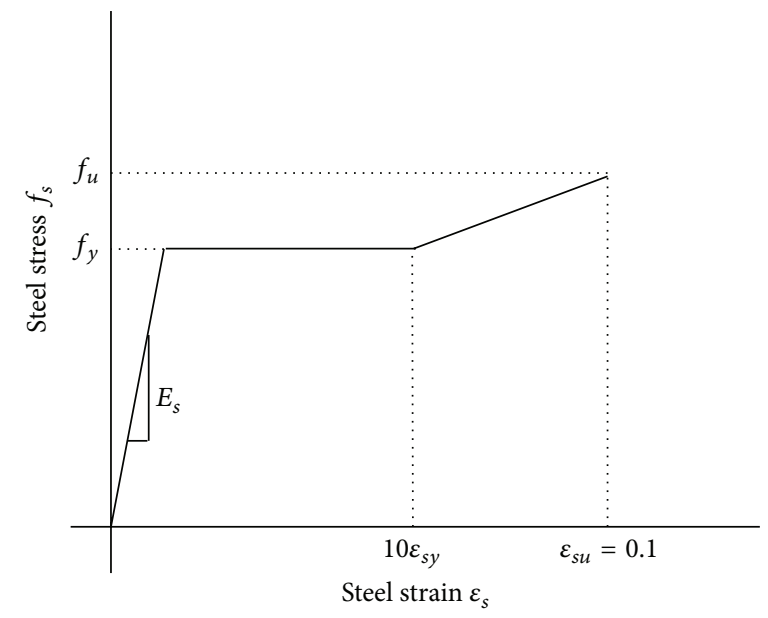

(c)

FIGURE 4: Material models for (a) plain concrete; (b) reinforcing bar; and (c) steel casing.

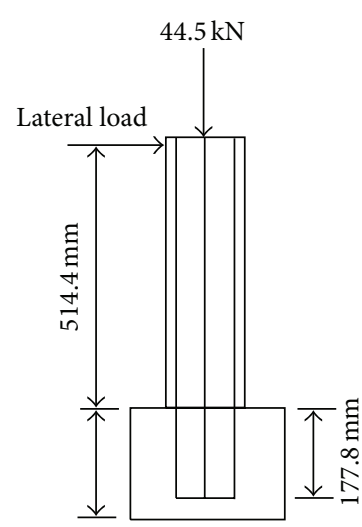

(a)

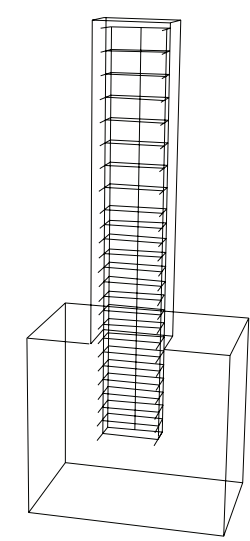

$l_{e}=177.8 \mathrm{~mm}(7 \mathrm{in})$

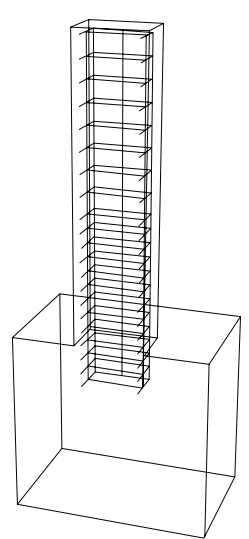

$l_{e}=76.2 \mathrm{~mm}(3 \mathrm{in})$

(b)

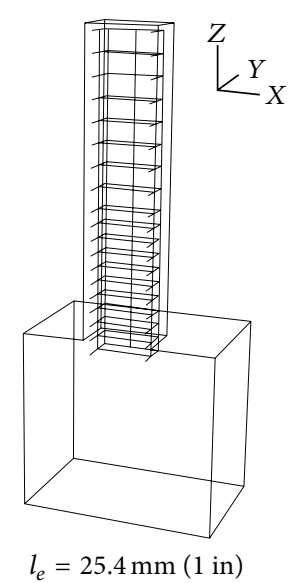

$l_{e}=25.4 \mathrm{~mm}(1 \mathrm{in})$

FIGURE 5: Verification model: (a) test specimen of Low and Moehle [6] and (b) verification model for different embedment depths of reinforcing bars. 


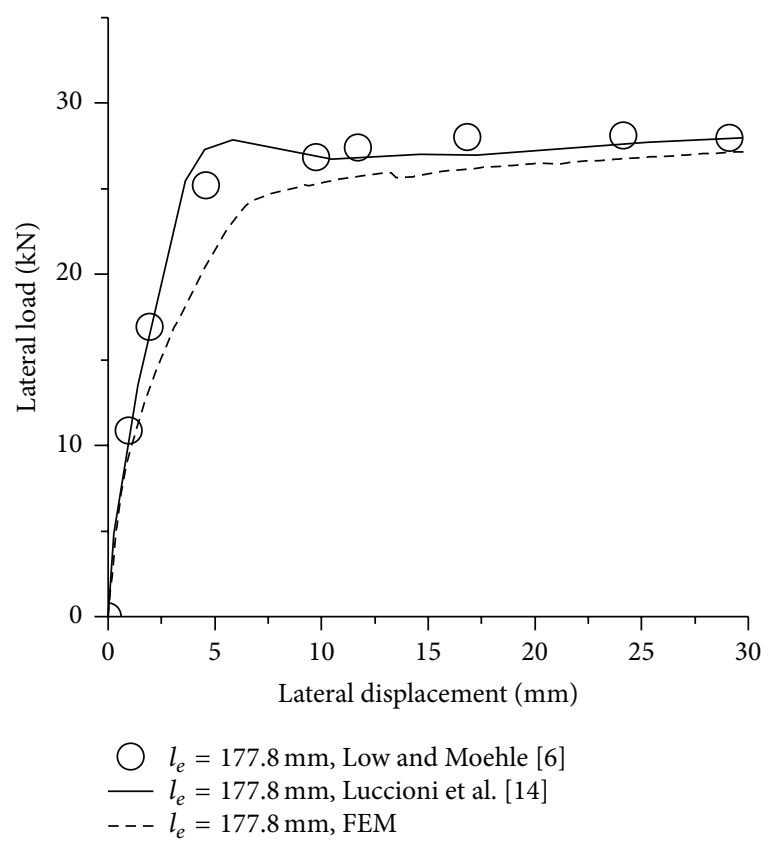

(a)

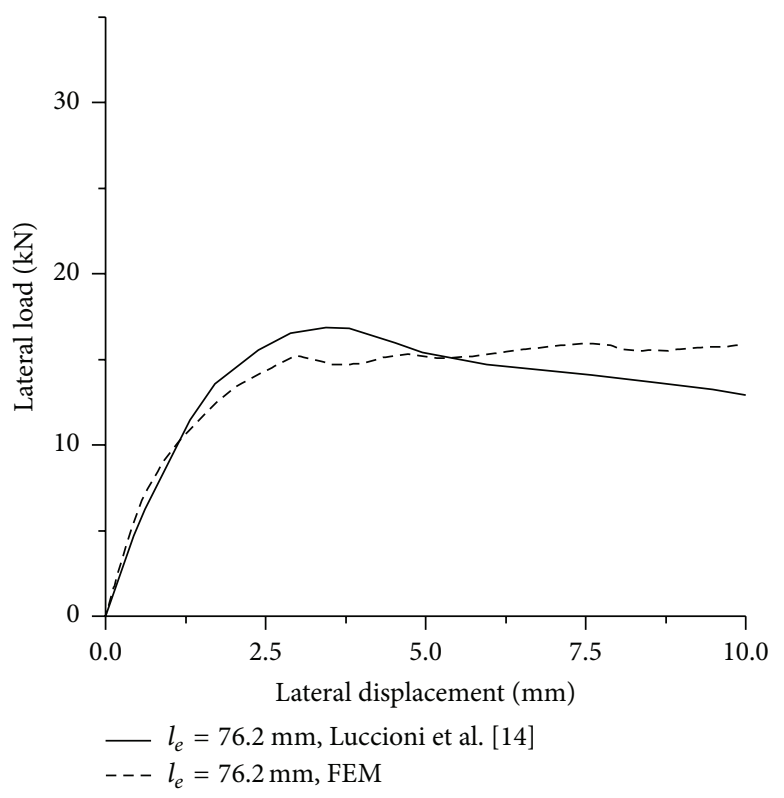

(b)

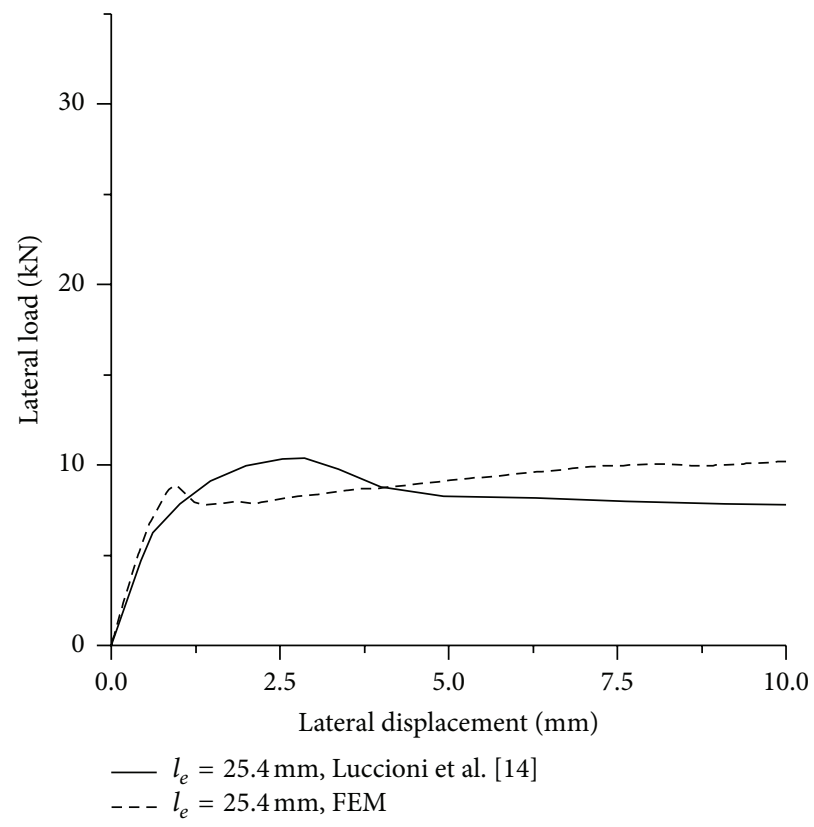

(c)

FIGURE 6: Verification results: (a) $l_{e}=177.8 \mathrm{~mm}$; (b) $l_{e}=76.2 \mathrm{~mm}$; and (c) $l_{e}=25.4 \mathrm{~mm}$.

TABLE 1: Properties of the reference model.

\begin{tabular}{lcccccccccc}
\hline$D_{1}(\mathrm{~mm})$ & $D_{1} / D_{2}$ & $D_{2} / t$ & $L_{1} / D_{1}$ & $L_{2} / D_{2}$ & $l_{e} / l_{d, \mathrm{AASHTO}}$ & $f_{c}^{\prime}(\mathrm{MPa})$ & $f_{y}(\mathrm{MPa})$ & $f_{y r}(\mathrm{MPa})$ & $P / P_{o, \mathrm{RC}}$ & F.C. \\
\hline 1,372 & 0.9 & 100 & 4 & 2 & 2.11 & 34.5 & 344.5 & 413.4 & 0.1 & 0.47 \\
\hline
\end{tabular}

on the CISS pile-to-RC pier connection behavior. The design details of the base model are presented in both of Table 1 and Figure 7. The length of the RC pier, $L_{1}$, was set as $4 D_{1}$, which was the marginal length for a flexural column. The optimal length of the CISS pile, $L_{2}$, is determined as $2 \mathrm{D}_{2}$ according to the criteria mentioned earlier. The yield stresses of the steel casing and reinforcing bar $\left(f_{y}\right.$ and $f_{y r}$, resp.) are taken as 344.5 $\mathrm{MPa}$ and $413.4 \mathrm{MPa}$, respectively. The ultimate stress of the steel casing, $f_{u}$, is $482.3 \mathrm{MPa}$. The compressive strength of concrete, $f_{c}^{\prime}$, is $34.5 \mathrm{MPa}$. $P_{o, \mathrm{RC}}$ shown in Table 1 is the squash 


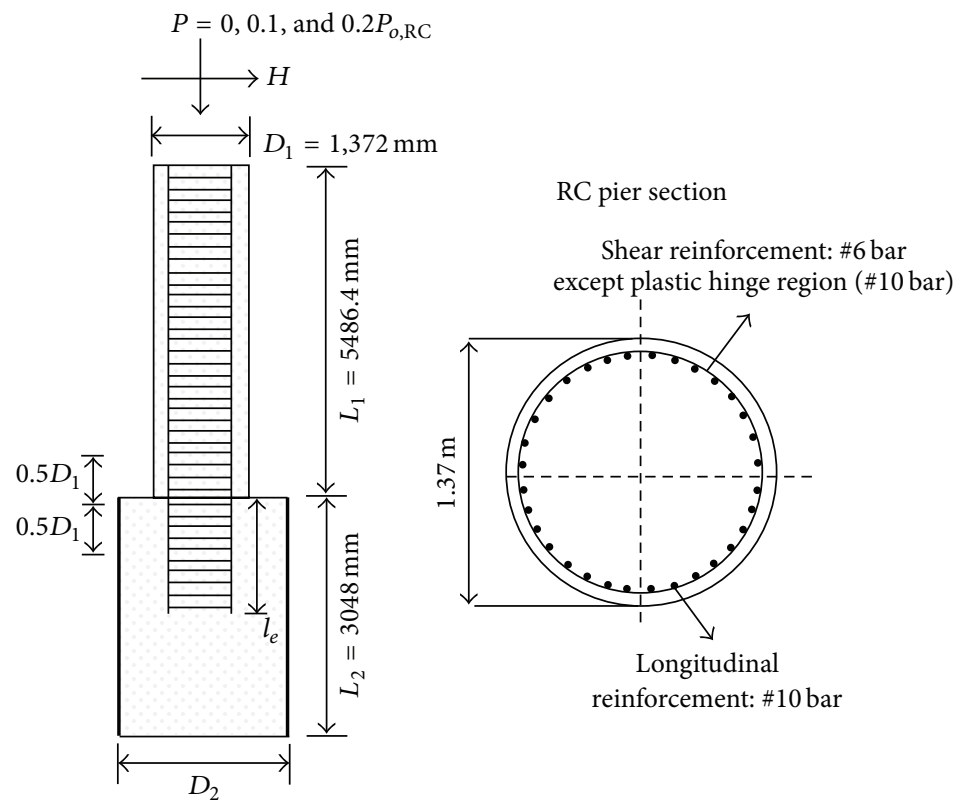

FIGURE 7: Analytical model for parametric study.

TABLE 2: Ranges of the values of each study parameter.

\begin{tabular}{ccccc}
\hline$D_{1} / D_{2}$ & $D_{2} / t$ & $l_{e} / l_{d, \mathrm{AASHTO}}$ & $P / P_{o, \mathrm{RC}}$ & F.C. \\
\hline $0.8-1.0$ & $80-120$ & $0.70-2.11$ & $0.0-0.2$ & $0.05-0.6$ \\
\hline
\end{tabular}

load of the RC pier and it is defined as $0.85 f_{c}^{\prime} A_{c}+f_{y b} A_{b t}$ according to ACI design code [12] where $A_{c}$ is the crosssectional area of the concrete, and $f_{y b}$ and $A_{b t}$ are the yield stress and the total area of the reinforcing bar, respectively. In Table $1, l_{e}$ is the embedment length of the reinforcing bar into the CISS pile. The axial load ratio, $P / P_{o, \mathrm{RC}}$, was set as 0.1 for the base model.

The RC pier is reinforced with $32 \# 10$ longitudinal reinforcing bars (the diameter of \#10 reinforcing bar is $32.26 \mathrm{~mm}$ ) as shown in Figure 7, resulting in a longitudinal reinforcement ratio of $1.8 \%$. The spiral reinforcement varied along the length of the pier. Outside of the plastic hinge region (outside of $\pm 0.5 D_{1}$ from the interface between the RC pier and the CISS pile, refer to Figure 7), \#6 spiral reinforcements spaced at $127 \mathrm{~mm}$ are used. The diameter of \#6 reinforcing bar is $19.05 \mathrm{~mm}$. It results in transverse reinforcement ratio of $0.33 \%$. Within the possible plastic hinge region, \#10 spiral spaced at $127 \mathrm{~mm}$ is used to meet the requirement of AASHTO LRFD design code [2] for the minimum shear reinforcement ratio in the plastic hinge region, where the transverse reinforcement ratio is equal to $0.94 \%$ for this region.

The parametric study is conducted by using the base model shown in Table 1 . The range of the value of each parameter is given in Table 2. The parameters are the embedment length $\left(l_{e}\right)$, the friction coefficient between the infilled concrete and the steel casing, the diameter to wall thickness ratio of the steel casing $\left(D_{2} / t\right.$ ratio), the axial load ratio, and the diameter ratio between the $\mathrm{RC}$ pier and the CISS pile $\left(D_{1} / D_{2}\right)$. The embedment, $l_{e}$, ranges from 0.7 to 2.11 . Four different values $(0.05,0.25,0.47$, and 0.6$)$ are used for the friction coefficient. Three different $D_{2} / t$ ratios $(80,100$, and 120) are used for the steel casing. Three different axial load ratios, $P / P_{o, \mathrm{RC}},(0,0.1$, and 0.2$)$ are selected. Three different values of $D_{1} / D_{2}(0.8,0.9$, and 1.0$)$ are used. Total 40 models are analyzed for a parametric study.

The primary parameter is the embedment length, $l_{e}$. The value of $l_{e}$ is normalized by the development length specified in AASHTO LRFD design code [2] for deformed bar in tension. $l_{d, \text { AASHTO }}$ is defined as

$$
l_{d, \mathrm{AASHTO}}=1.25 \frac{A_{b} f_{y b}}{\sqrt{f_{c}^{\prime}}}
$$

for a \#10 bar or smaller bar where $A_{b}$ is the area of the

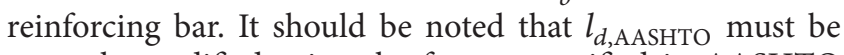
properly modified using the factors specified in AASHTO LRFD design code [2] for various conditions and locations of reinforcing bars. The details of the modification factors can be found in AASHTO LRFD design code [2]. The axial load is applied first. Then, the lateral displacement at the top of the RC pier is monotonically increased up to $254 \mathrm{~mm}$, which is approximately $4.6 \%$ total drift of the RC pier. This value is sufficient to develop full plastic action in the systems.

3.2. Results of Parametric Study. Figures 8(a) and 8(b) show the crack pattern and failure mechanism for the analysis models with $l_{e} / l_{d \text {,AASHTO }}=0.7$ and 2.11 , respectively. It is noted that the distribution of the maximum equivalent tensile plastic strain of the concrete shown in Figure 8 represents the cracking in the concrete [7]. Let us consider the model 


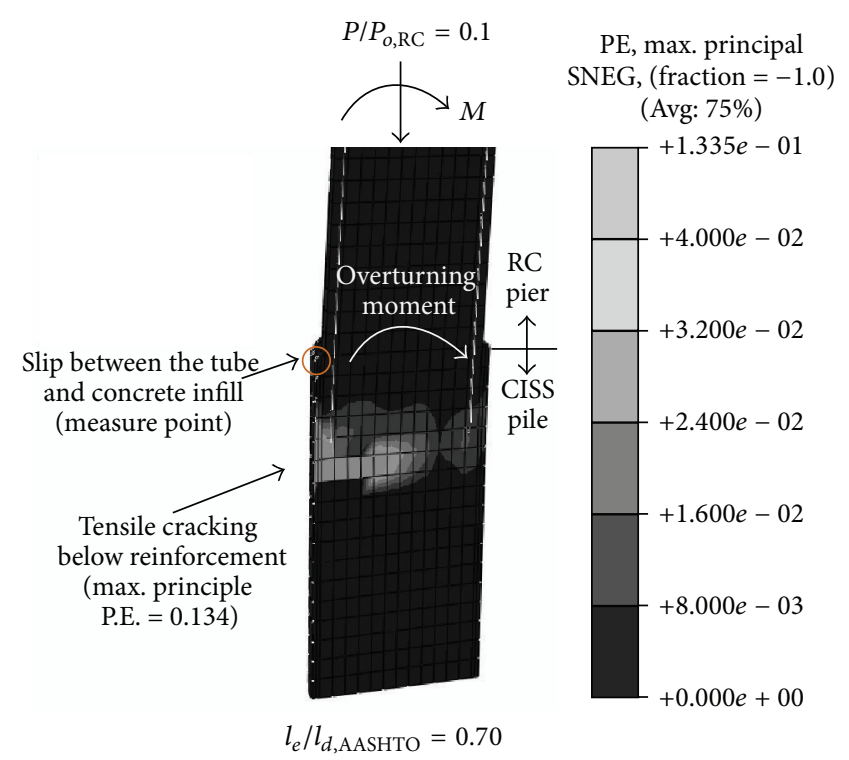

(a)

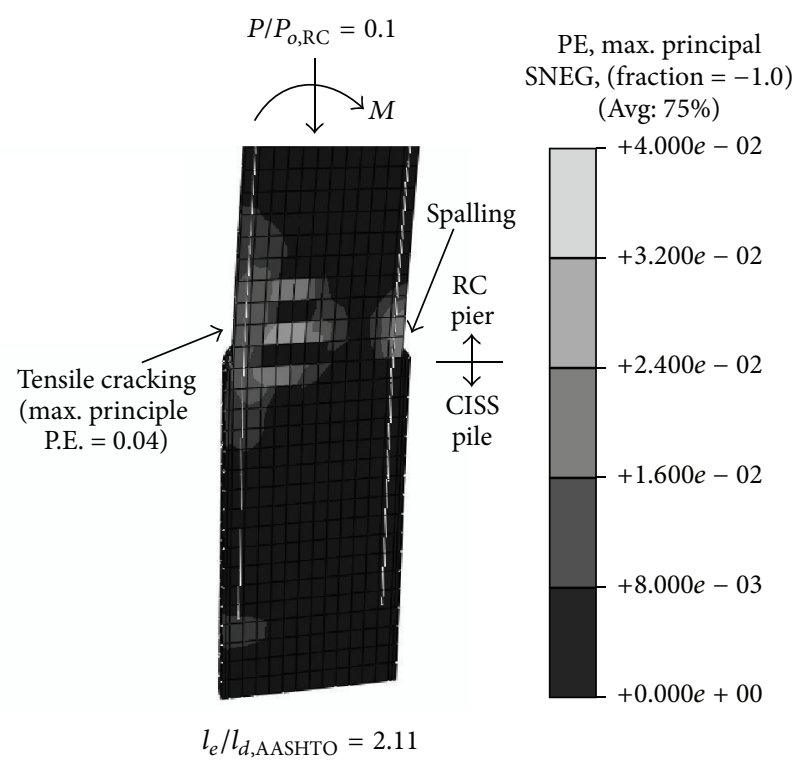

(b)

FIGURE 8: Crack pattern and failure mechanism for different embedment lengths: (a) $l_{e}=0.70 l_{d, \mathrm{AASHTO}}$ and (b) $l_{e}=2.11 l_{d, \mathrm{AASHTO}}$.

with $l_{e} / l_{d, \text { AASHTO }}=0.7$ first. Figure 8 (a) shows that a single predominant crack forms in the steel casing portion at the end of the embedded reinforcement. Following the opening of the crack, the reinforcement in the RC pier is pulled out from the concrete and the RC pier is separated from the CISS pile. This damage pattern resulted in an excessive rotation of RC pier. This is an undesirable response mode, since it limits the inelastic deformation capacity of the system. On the other hand, a different failure mechanism occurs for deeper embedment length cases. The tension side is cracked while the spalling of the cover concrete is observed on the compression side and a significant inelastic action is sustained at the base of RC pier for $l_{e} / l_{d \text {,AASHTO }}=2.11$ case, as shown in Figure $8(\mathrm{~b})$. This is a desirable inelastic response mechanism, for which a stable plastic hinge forms including cracking and plastic action in the longitudinal reinforcement in tension and compression side.

Figure 9 shows analytical results for four different embedment lengths of the reinforcing bar. The embedment lengths

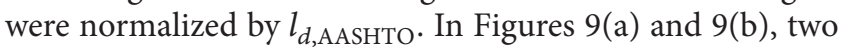
different drift measures were used. "Total drift" indicates the relative rotation of the RC pier to the top of CISS pile, as shown in Figures 10(a) and 10(b). "Pier drift" in this study is defined as the total drift minus the rigid body rotation of the RC pier due to the slip between the steel casing and the infilled concrete, as shown in Figure 10(c). Thus, the pier drift indicates the pure flexural rotation of the RC pier. It should be noted that the difference between the total and the pier drift represents the rigid body rotation of the $\mathrm{RC}$ pier due to a relative slip between the steel casing and the infilled concrete. The $y$-axis in Figures 9(a) and 9(b) denotes the moment at the base of the RC pier, $M$, normalized by the nominal moment strength of the RC pier, $M_{n}$, obtained from general strain compatibility method specified in ACI design code [12].
When $l_{e}$ is larger than $l_{d \text {,AASHTO }}$, the ultimate moment at the base was $6 \%$ larger than $M_{n}$, as shown in Figures 9(a) and $9(\mathrm{~b})$, indicating the plastic action in the RC pier. The relative slip between the steel casing and the infilled concrete is measured at the end of tension side of the CISS pile (refer to Figure 8 ). When embedment length is $1.4 l_{d \text {,AASHTO, the slip is }}$ approximately $0.005 D_{1}(6.9 \mathrm{~mm})$ at $3 \%$ total drift, as shown in Figure 9(c). The slip increased as the embedment length decreases. In addition, for $l_{e} / l_{d \text {, АASHTO }}=0.7$, the moment demand of the RC pier does not reach $M_{n}$. Furthermore, the comparison of Figures 9(a) and 9(b) reveals that most of the drift for the analysis model with shorter embedment lengths results from the rotation of the connection. This result suggests that the excessive slip between the infilled concrete and the steel casing, which is generated by the overturning demands of RC pier, compromises the response of the system, and it can be seen that the embedment length has a significant impact on the performance of the system.

Figure 11 shows selected results of the parametric study when $l_{d \text {,AASHTO }}=0.7$; that is, the embedment length is smaller than the development length specified in AASHTO LRFD [2] design code. Figures 11(a), 11(b), 11(c), and 11(d) show the effects of the $D_{2} / t$ ratio, the friction coefficient (F.C. in the figure), the axial load ratio $P / P_{o, \mathrm{RC}}$, and $D_{1} / D_{2}$ ratio, respectively. It should be noted that the dimension $D_{1}$ is fixed when $D_{1} / D_{2}$ is varied, and the drift in $x$-axis is corrected for the translation of the CISS pile only (i.e., $x$-axis represents the total drift). These variables are chosen for the following reasons: (1) the $D_{2} / t$ ratio is a fundamental variable, which impacts the local instability of the steel tube and the strength of a CISS pile; (2) it is assumed that the friction coefficient between the steel casing and infilled concrete varies within the range of 0.05 and 0.6. According to Baltay and Gjelsvik [15], the friction coefficient between the steel and the concrete 


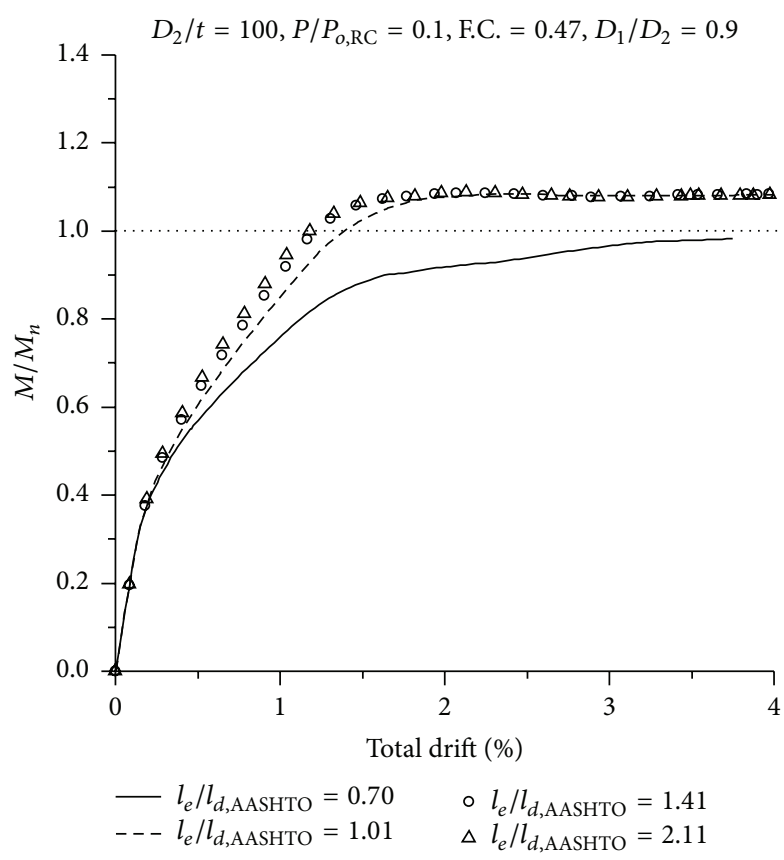

(a)

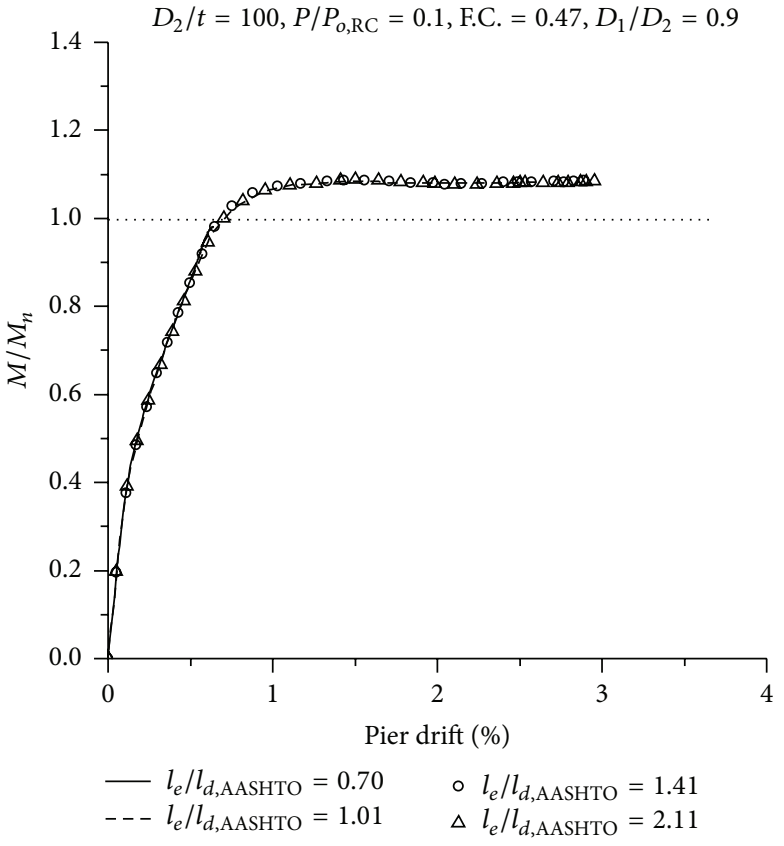

(b)

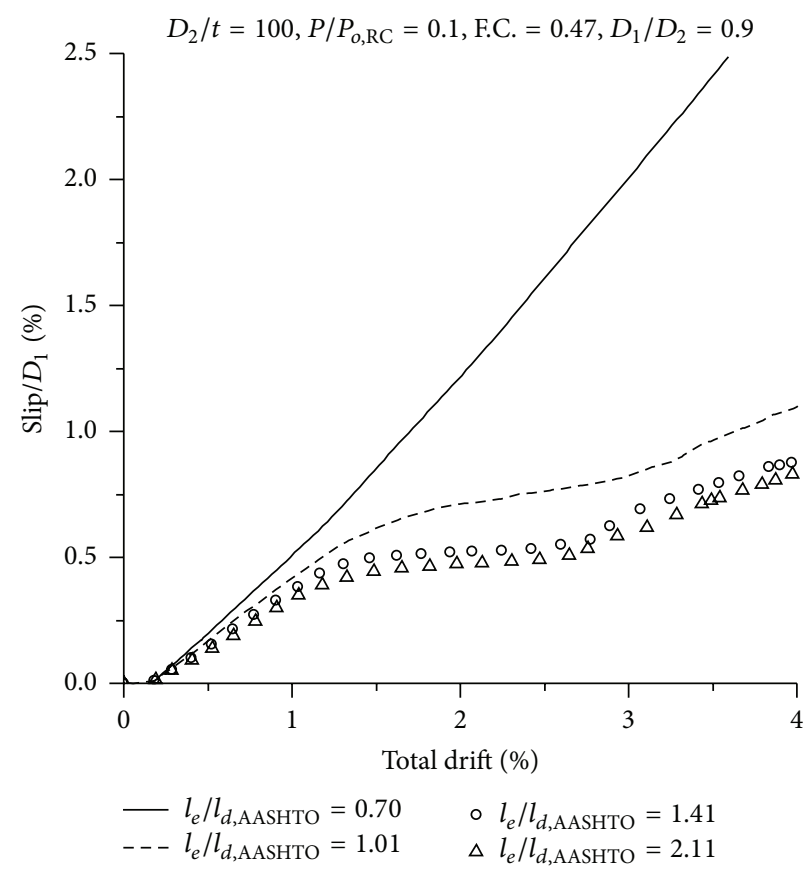

(c)

FIGURE 9: Effect of $l_{e}$ : (a) $M / M_{n}$ vs. total drift; (b) $M / M_{n}$ vs. pier drift; and (c) Slip/ $D_{1}$ vs. total drift.

varies from 0.3 to 0.6 , and the mean value is equal to 0.47 . The variation in the friction coefficient represents the quality of the interface reflecting the effect of dirt or other debris in a steel casing. For example, the friction coefficient may decrease with increasing the dirt or other debris in the steel casing. In this study, a small friction coefficient such as 0.05 is adopted. Such conservative value (F.C. $=0.05)$ is adopted for the analysis to simulate the extreme case due to lack of experimental data for the friction coefficient of the CISS pile;
(3) the variation in the axial load affects the flexural strength of RC pier. The practical range of the axial load ratio $\left(P / P_{o, R C}\right.$ ranges from 0 to 0.2 ) is investigated; and (4) the diameter ratio is investigated as a primary design parameter to consider its impact on the response.

Figure 11 shows that the strength is increased with (1) a decrease in the $D_{2} / t$ ratio of the CISS pile, (2) a decrease in the $D_{1} / D_{2}$ ratio $\left(0.8<D_{1} / D_{2}<1\right)$, (3) an increase in friction coefficient between the steel casing and the infilled 


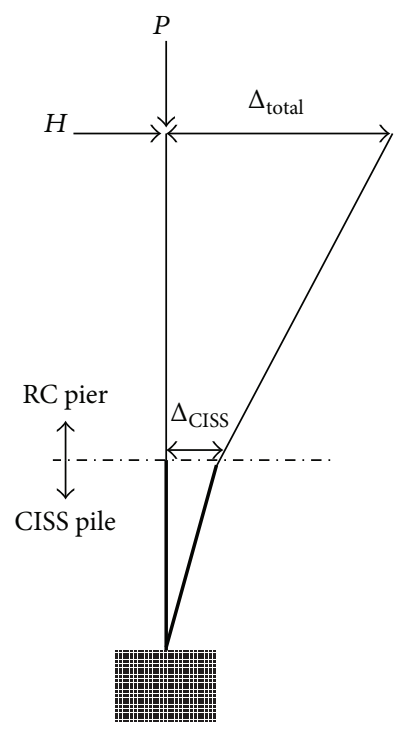

(a)

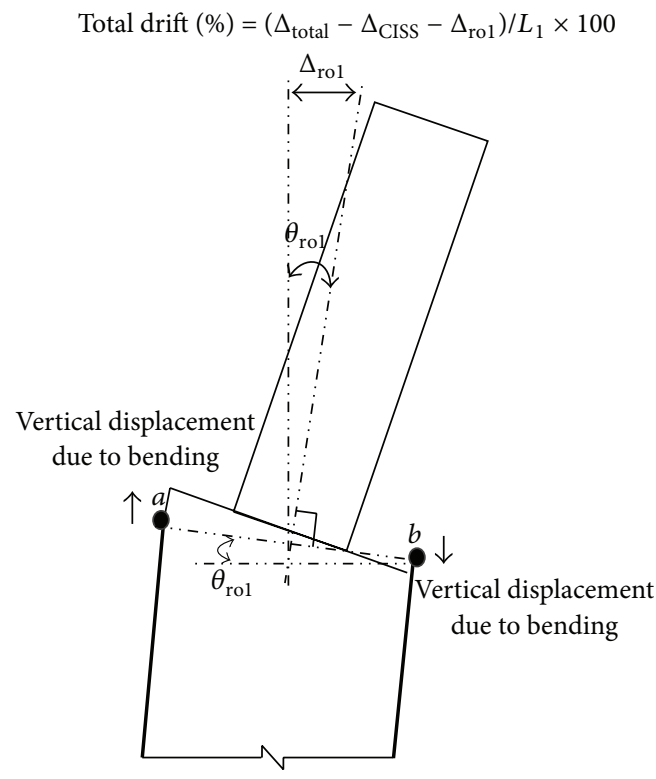

(b)

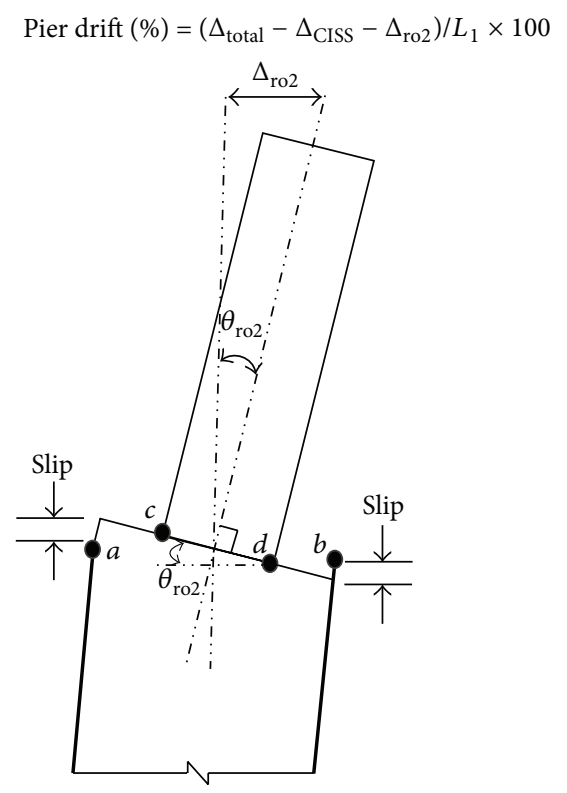

(c)

FIGURE 10: Definition of total and pier drift: (a) deflection of CISS pile and RC pier; (b) definition of total drift; and (c) definition of pier drift.

concrete, and (4) an increase in the axial load ratio, $P / P_{o, \mathrm{RC}}$, up to a value of 0.2 . However, although some of these models reached the nominal moment strength, $M_{n}$, they still resulted in a pull-out failure, which is not desirable. An increase in the axial load ratio and the friction coefficient provides the additional resistance to a pull-out failure for the analysis model shown in Figure 11, and it results in a higher strength when the embedment depth is not sufficient.

Figure 12 shows the results of parametric study for the longer embedment length $\left(l_{e} / l_{d \text {, AASHTO }}=1.41\right)$. For all analysis results, cracking in tension and the spalling in compression side at the base of RC pier are observed, and the effects of $D_{2} / t$ ratio, friction coefficient, and $D_{1} / D_{2}$ ratio are negligible since the strength of the connection is enough to develop the plastic hinge, as shown in Figures 12(a), 12(b), and $12(\mathrm{~d})$. Furthermore, it can be found that increase in the axial load and decrease in $D_{1} / D_{2}$ ratio result in increase in stiffness, as shown in Figures 12(c) and 12(d).

From Figure 12(c), a strength degradation is observed for the analysis model with $P / P_{o, R C}=0.2$. Generally, a brittle failure occurs when the applied axial load exceeds the axial load of the balanced point in a $P-M$ interaction curve for a reinforced concrete column because the concrete crushing occurs before the yielding of the reinforcing bar. The same failure mode is observed for the analysis model having $P / P_{o, \mathrm{RC}}=0.2$.

A key aspect of adequate development length is the ability to develop strains beyond the yield strain in the anchored bar. This is studied for each of the models. Figure 13 shows the relationship between the axial strain in compression (or tension) reinforcing bar at $3 \% \mathrm{drift}$ and $l_{e} / l_{d \text {,AASHTO }}$. It is noted that the axial strain in reinforcing bar is obtained at the interface between the CISS pile and RC column. When $l_{e} / l_{d \text {,AASHTO }}$ is less than 1 , the majority of the models did not reach strains that exceed the yield strain, $\varepsilon_{y}$, as shown in Figures 13(a) and 13(b). For the analysis models with $l_{e} / l_{d \text {,AASHTO }}=1.01$, there is a variation in the achieved axial strain of the reinforcing bar. Some of the analysis results do not reach to yield strain. In particular, this is true for models with very low friction coefficient $($ F.C. $=0.05)$. Furthermore, when $l_{e} / l_{d \text {,AASHTO }}$ is larger than 1.5 , strain in the tension reinforcing bar approximately reaches to $5 \varepsilon_{y}$, as shown in Figure $13(\mathrm{~b})$. When $D_{1} / D_{2}$ is equal to 1 (i.e., the diameter of the CISS pile and RC pier is the same), the strain in compression reinforcing bar is relatively high compared with the other cases. This is because compression reinforcing bar is slightly buckled due to lack of sufficient concrete area at interface between the CISS pile and RC pier. Taken as whole, the analysis results show that $l_{e} / l_{d \text {,AASHTO }}$ should be larger than approximately 1.5 to achieve considerable inelastic deformation in reinforcing bar.

Figure 14 represents variation in the moment capacity of the connection with embedment length of reinforcing bar. For values of $l_{e} / l_{d \text {, AASHTO }}=0.70$ and 1.01 , some of the analysis results do not achieve sufficient moment capacity of the connection. In particular, this is noted for the models with low friction coefficient values, as shown in Figure 14. The analysis results with the friction coefficient of 0.05 give low bound for the moment capacity of the CISS pile-toRC pier connection. These results show that $l_{e} / l_{d, \text { AASHTO }}$ should be larger than approximately 1.25 . Thus, a minimum value of $l_{e} / l_{d \text {,AASHTO }}=1.5$ is recommended to develop the full strength of the CISS pile-to-RC pier connection and considerable inelastic deformation in reinforcing bar at the same time. However, this recommendation is based on an analytical study only without experimental results. The additional experimental research is needed to develop robust design equation for the minimum embedment length of the pier longitudinal reinforcement into the CISS pile. 


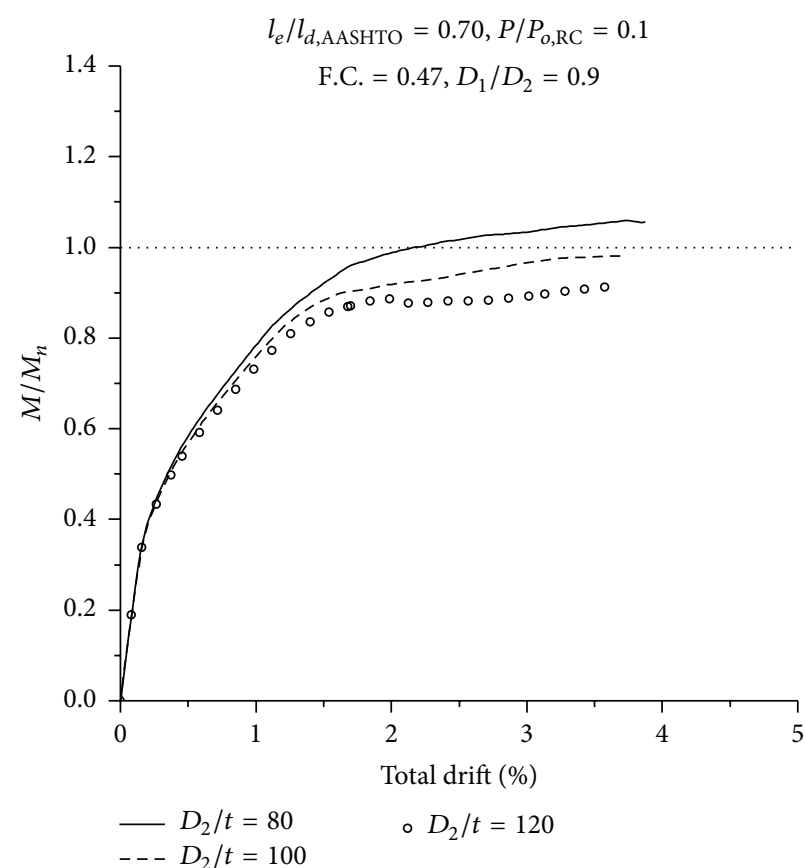

(a)

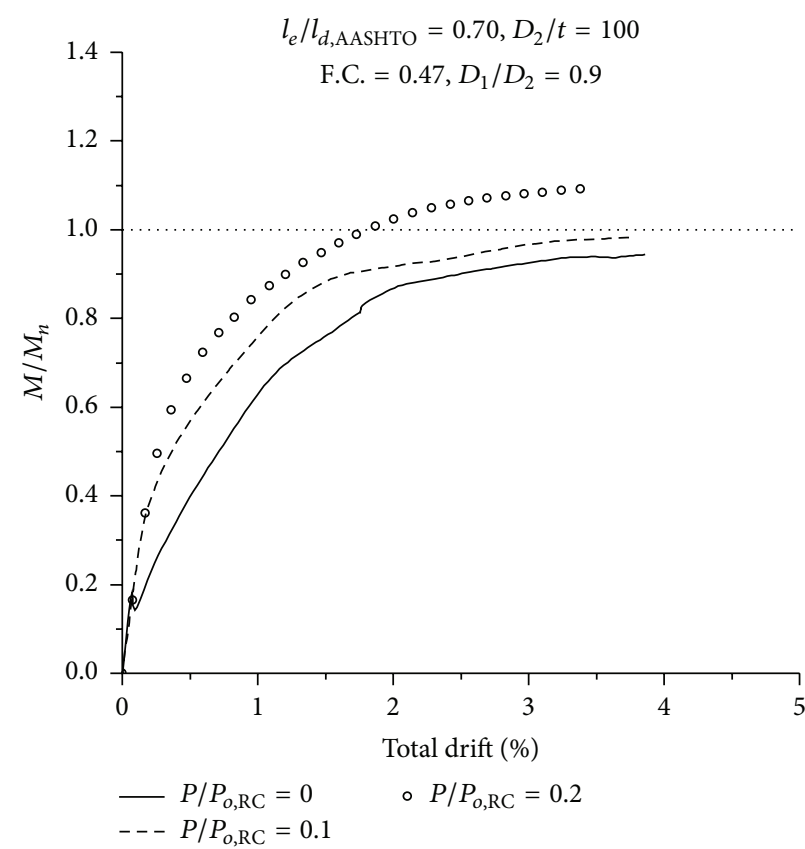

(c)

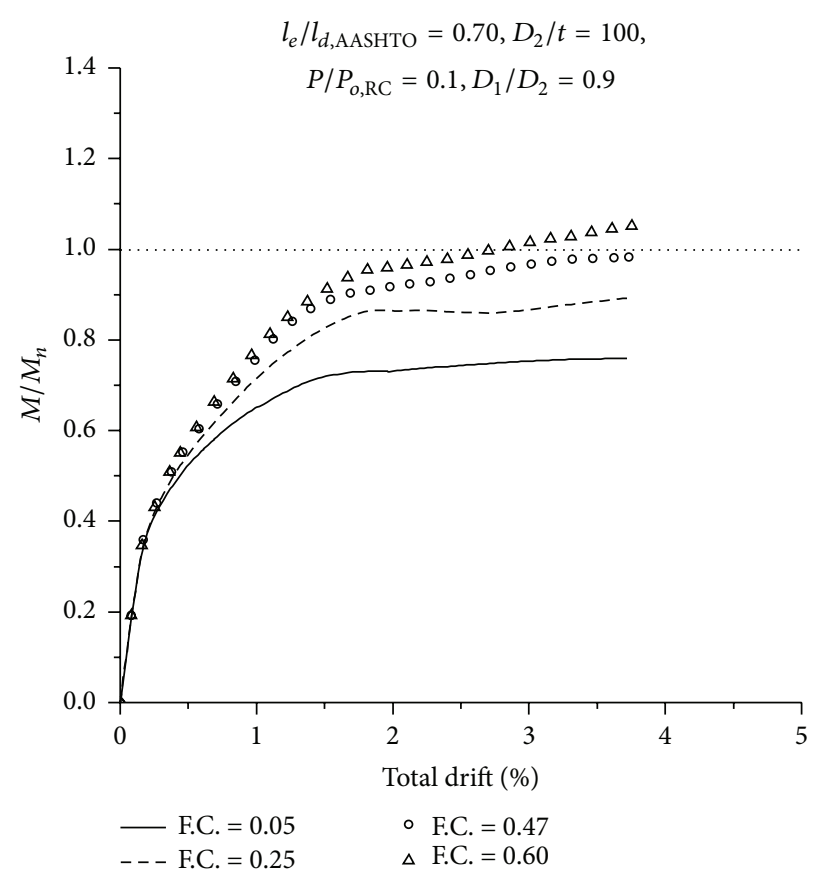

(b)

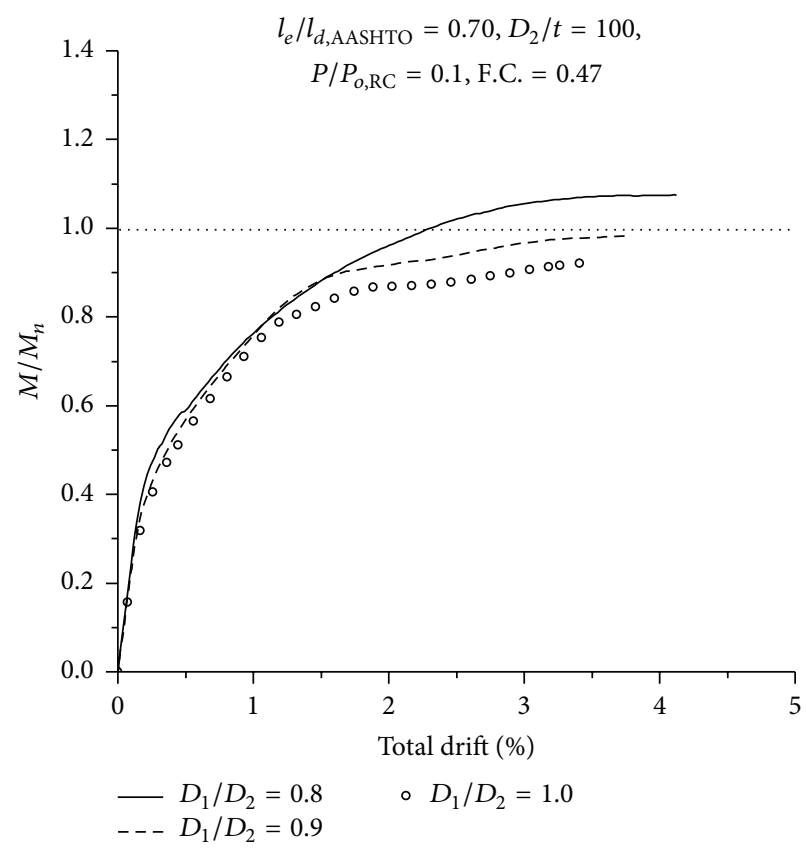

(d)

FIGURE 11: Impact of parameters for $l_{e} / l_{d, \mathrm{AASHTO}}=0.70$ : (a) effect of $D_{2} / t$ ratio; (b) effect of friction coefficient; (c) effect of axial load ratio; and (d) effect of $D_{1} / D_{2}$ ratio.

\section{Summary and Conclusions}

This study presents a nonlinear FE analysis result of the CISS pile-to-RC pier connection considering the steel-concrete interface behavior. The effect of the embedment length of the reinforcing bars to the strength of the RC pier is evaluated. The effect of the friction coefficient between the steel casing and the infilled concrete is also evaluated. Depending on the embedment length of the reinforcing bar that extends into the CISS pile, two different failure mechanisms are observed. For the short embedment lengths, the pull-out failure is noted, while a desirable plastic action at the bottom of the RC pier is generated when the embedment depth is sufficient.

The effects of key parameters are evaluated by conducting a parametric study. For a short embedment length, there is an increased likelihood of pull-out failure. The effects of 


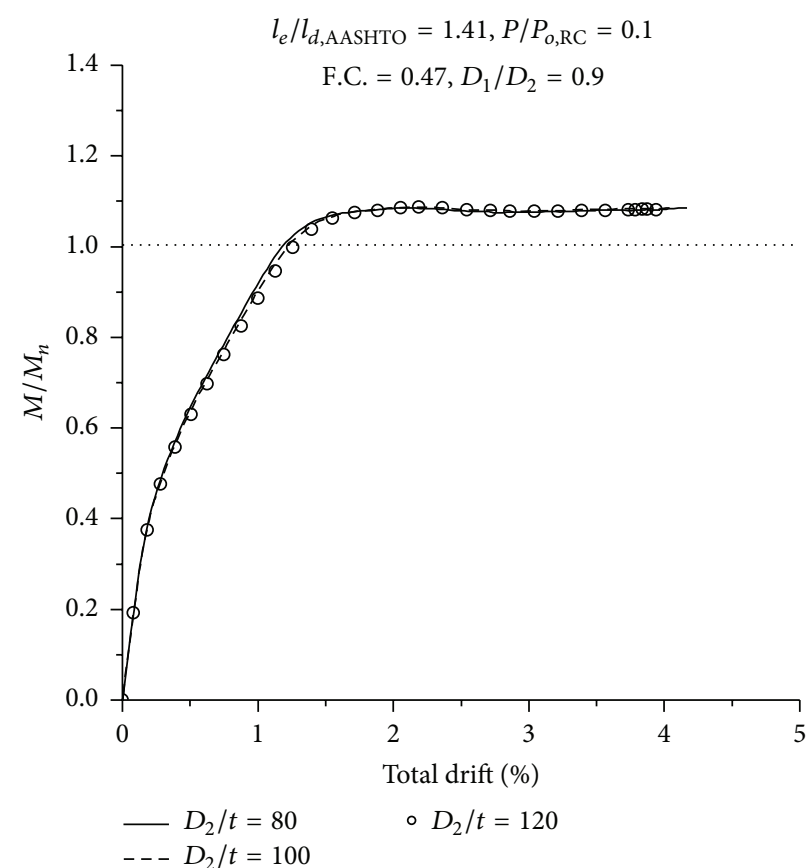

(a)

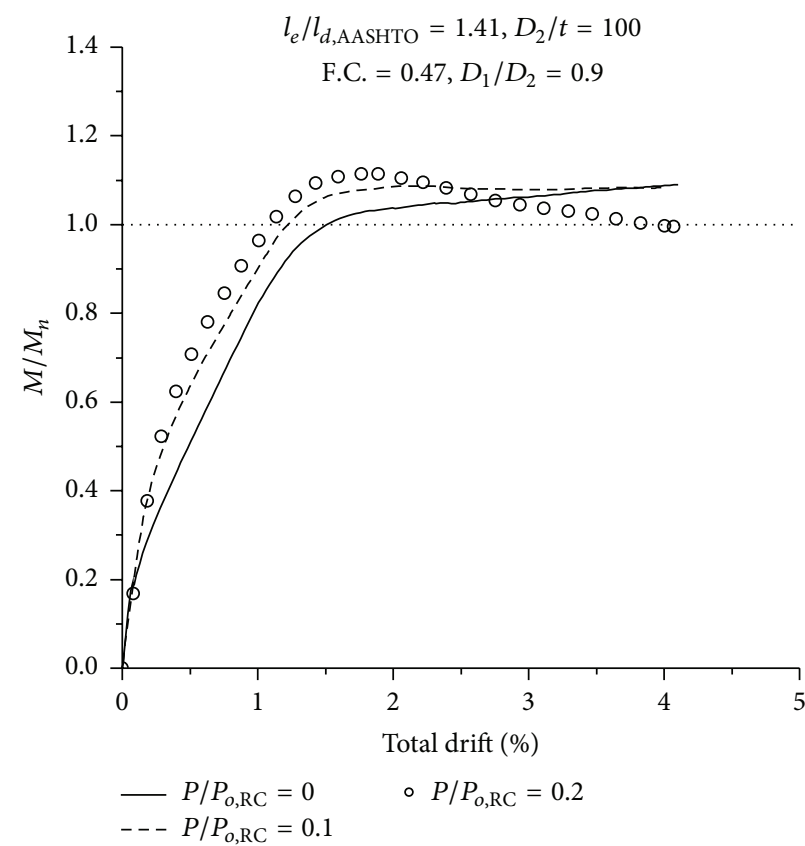

(c)

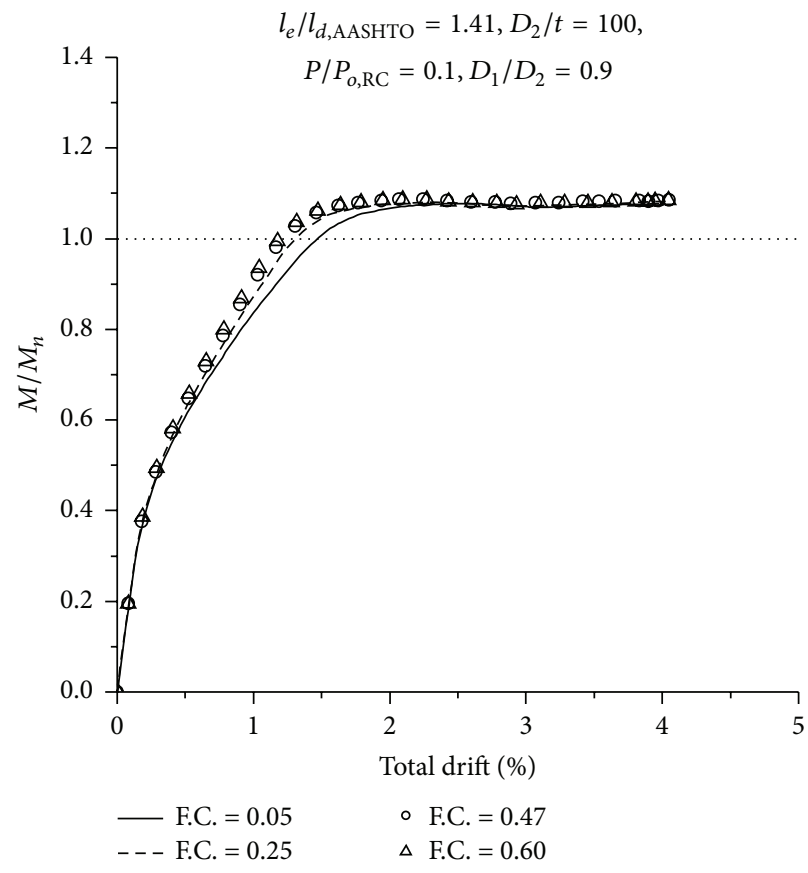

(b)

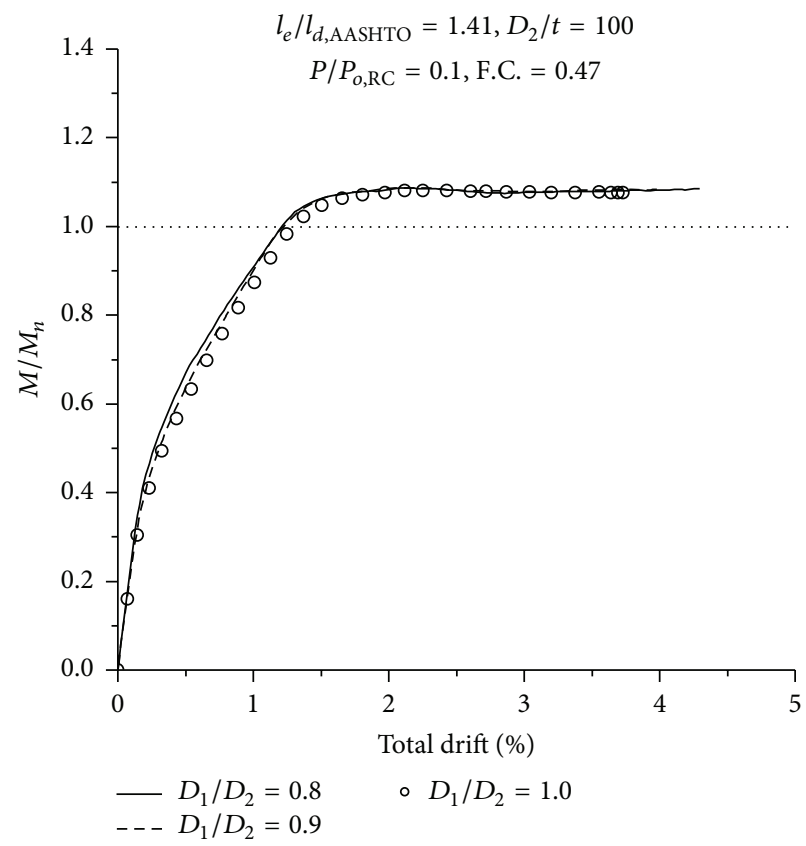

(d)

Figure 12: Results of parametric study $\left(l_{e} / l_{d, \text { AASHTO }}=1.41\right)$ : (a) effect of $D_{2} / t$ ratio; (b) effect of friction coefficient; (c) effect of axial load ratio; and (d) effect of $D_{1} / D_{2}$ ratio.

$D_{2} / t$ ratio, friction coefficient, and $D_{1} / D_{2}$ ratio are negligible when the embedment length of reinforcing bar is sufficient. Furthermore, a satisfactory performance in terms of strength, stiffness, and strain demand is achieved for well-anchored models. Based on the parametric study, it is suggested that $l_{e} / l_{d \text {,ААSHTO }}$ should be larger than 1.5 to develop the full strength of the CISS pile-to-RC pier connection and a considerable inelastic deformation in reinforcing bar simultaneously.

\section{Conflict of Interests}

The authors declare that there is no conflict of interests regarding the publication of this paper. 


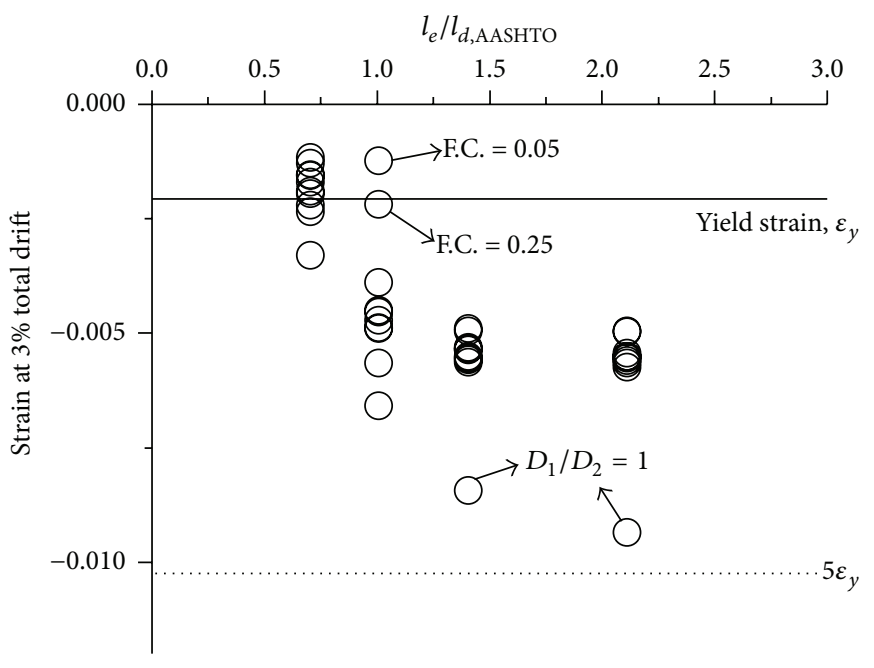

Compression reinforcing bar

(a)

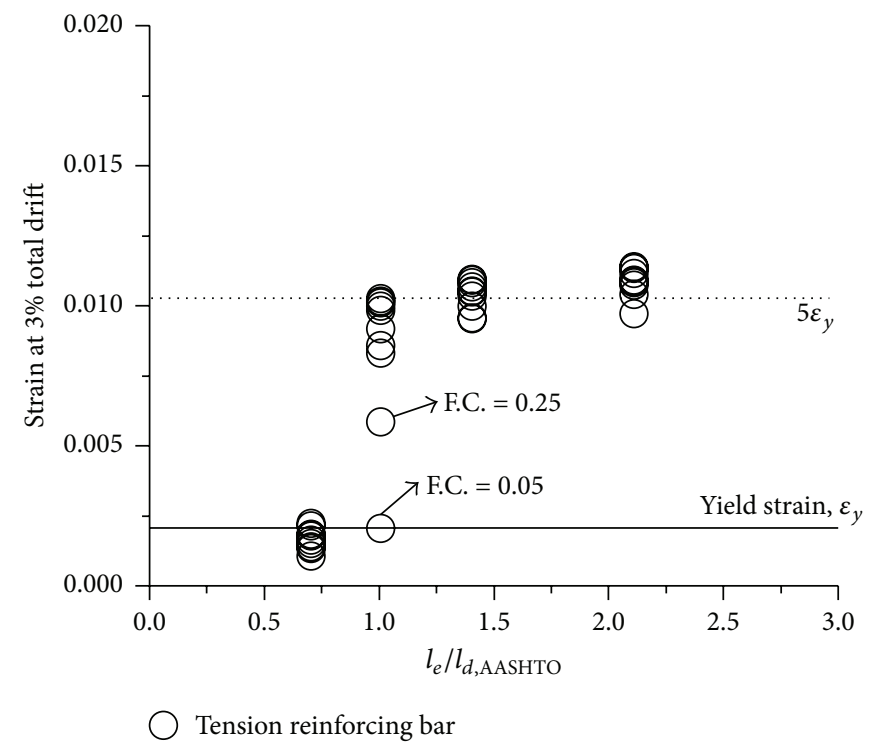

(b)

Figure 13: Variation in strain of reinforcement at 3.5\% of drift with $l_{e} / l_{d, \mathrm{AASHTO}}$ : (a) compression reinforcing bar and (b) tension reinforcing bar.

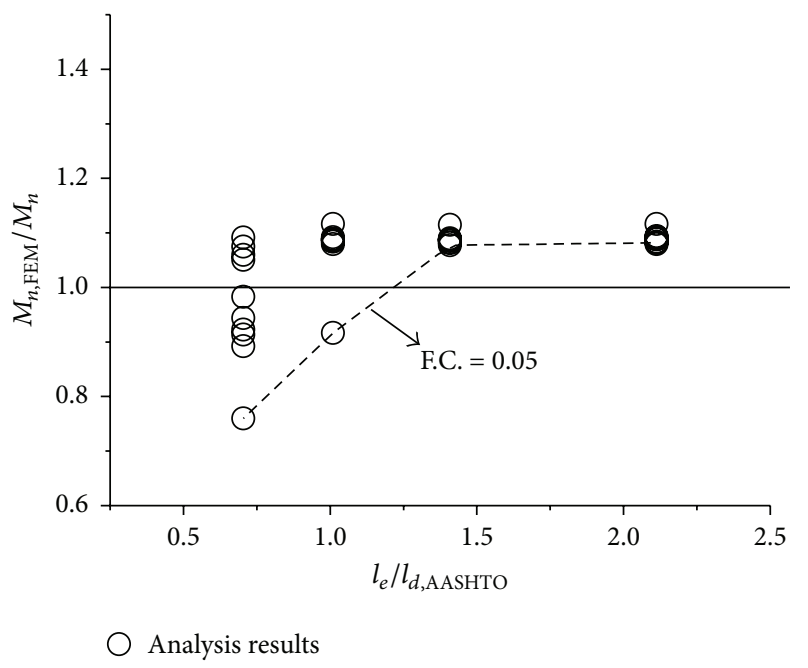

FIGURE 14: Variation in moment capacity of the connection with embedment length of reinforcement.

\section{Acknowledgments}

This research was supported by a grant from R\&D Program of the Korea Railroad Research Institute, Republic of Korea, and by a grant (15RTRPB069124-03) from Railroad Technology Research Program funded by Ministry of Land, Infrastructure and Transport of Korean Government. Also, it is partially supported by a Korea University grant.

\section{References}

[1] C. W. Roeder and D. E. Lehman, "Initial investigation of reinforced concrete filled tubes for use in bridge foundations,"
Report WA-RD 776.2, Washington Department of Transportation, Olympia, Wash, USA, 2012.

[2] AASHTO, AASHTO LRFD Bridge Design Specification, Washington, DC, USA, 5th edition, 2010.

[3] P. F. Silva, S. Sritharan, F. Scible, and M. J. N. Priestley, "Fullscale test of the Alaska cast-in-place steel shell three column bridge bent," Tech. Rep. SSRP 98/13, Alaska Department of Transportation and Public Facilities, Juneau, Alaska, USA, 1999.

[4] M. Gebman, S. Ashford, and J. Restrepo, "Investigation of the axial load transfer mechanism in cast-in-steel-shell pile," Report TR-04/02, Department of Structural Engineering, University of California, San Diego, San Diego, Calif, USA, 2004.

[5] M. Gebman, S. Ashford, and J. Restrepo, "Investigation of the axial load transfer through shear rings in cast-in-steel-shell iles," Tech. Rep. TR-05/02, Department of Structural Engineering, University of California, San Diego, Calif, USA, 2005.

[6] S. S. Low and J. P. Moehle, "Experimental study of reinforced concrete columns subjected to multi-axial cyclic loading," EERC Report 87/14, Earthquake Engineering Research Center, University of California, Berkeley, Berkeley, Calif, USA, 1987.

[7] ABAQUS, ABAQUS Analysis User's Manual Version 6.9-2, Dassault Systemes Simulia, Providence, RI, USA, 2009.

[8] J. Moon, C. W. Roeder, D. E. Lehman, and H.-E. Lee, "Analytical modeling of bending of circular concrete-filled steel tubes," Engineering Structures, vol. 42, pp. 349-361, 2012.

[9] J. Moon, D. E. Lehman, C. W. Roeder, and H.-E. Lee, "Strength of circular concrete-filled tubes with and without internal reinforcement under combined loading," Journal of Structural Engineering ASCE, vol. 139, no. 12, Article ID 04013012, 2013.

[10] L. P. Saenz, "Discussion of 'equation for the stress-strain curve of concrete' by P. Desai, and S. Krishnan," ACI Structural Journal, vol. 61, pp. 1229-1235, 1964.

[11] T. T. C. Hsu and Y.-L. Mo, Unified Theory of Concrete Structures, John Wiley \& Sons, Hoboken, NJ, USA, 2nd edition, 2010. 
[12] ACI, Building Code Requirements for Structural Concrete and Commentary, American Concrete Institute, Farmington Hills, Mich, USA, 2011.

[13] J. B. K. Pang, M. O. Eberhard, and J. F. Stanton, "Large-bar connection for precast bridge bents in seismic regions," Journal of Bridge Engineering, vol. 15, no. 3, pp. 231-239, 2010.

[14] B. M. Luccioni, D. E. López, and R. F. Danesi, "Bond-slip in reinforced concrete elements," Journal of Structural Engineering, vol. 131, no. 11, pp. 1690-1698, 2005.

[15] P. Baltay and A. Gjelsvik, "Coefficient of friction for steel on concrete at high normal stress," Journal of Materials in Civil Engineering, vol. 2, no. 1, pp. 46-49, 1990. 

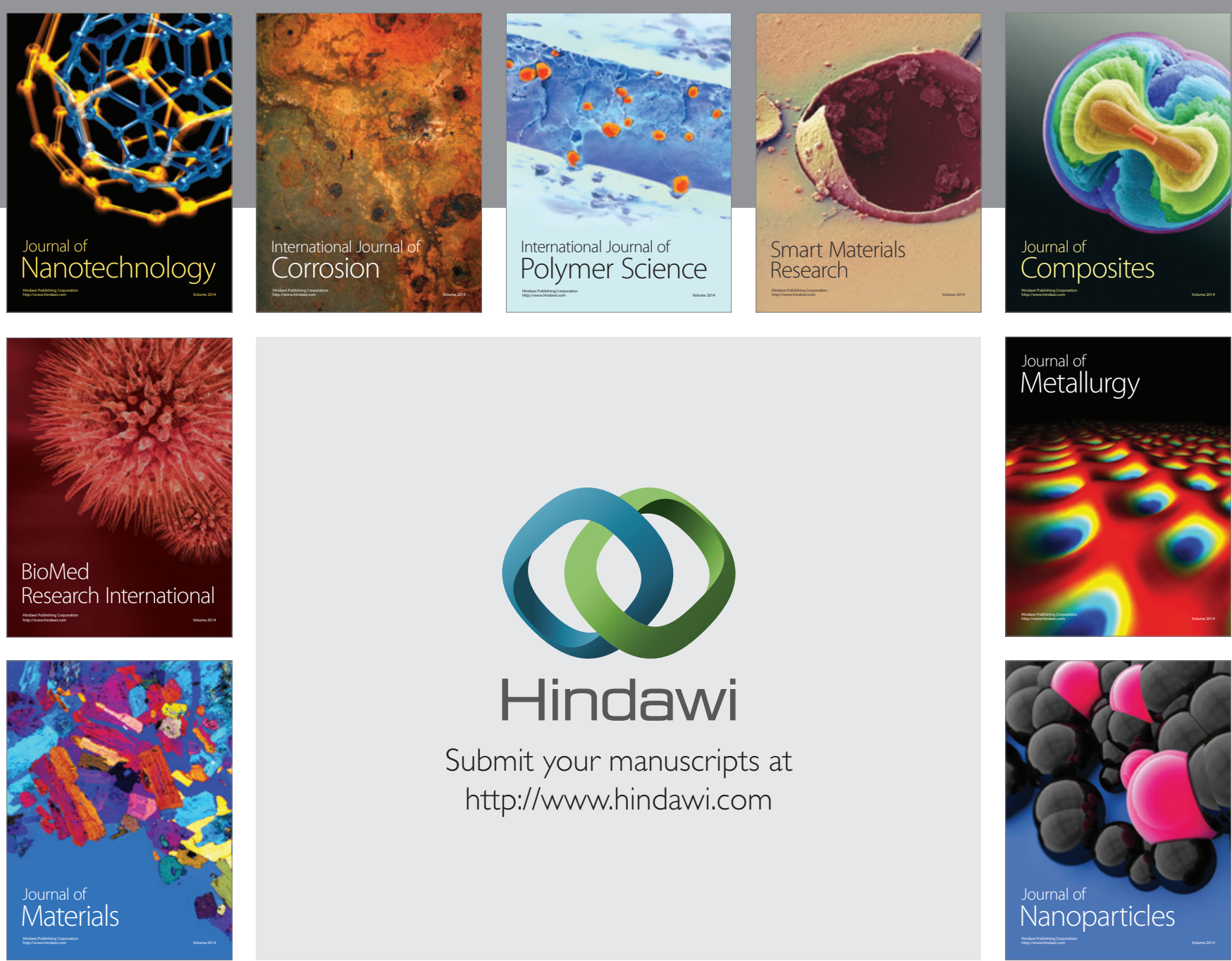

\section{Hindawi}

Submit your manuscripts at

http://www.hindawi.com

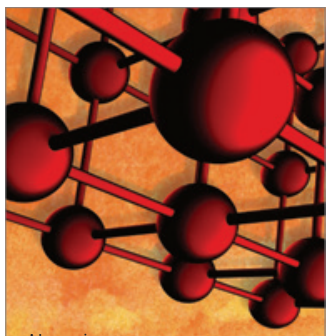

Materials Science and Engineering
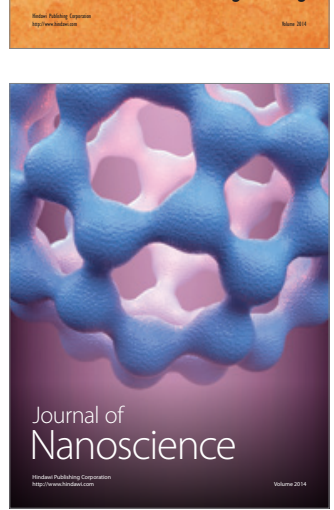
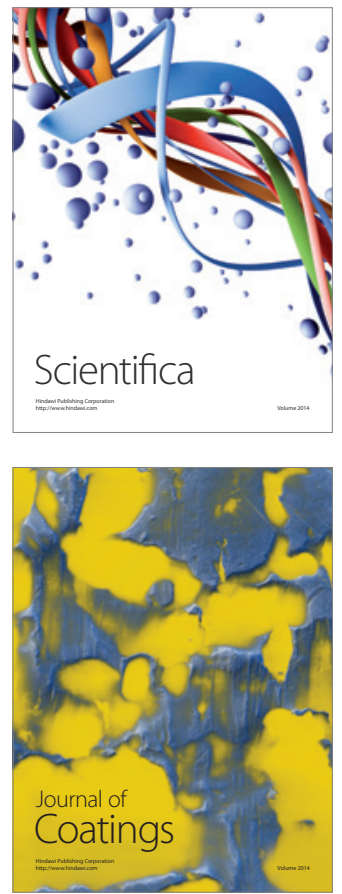
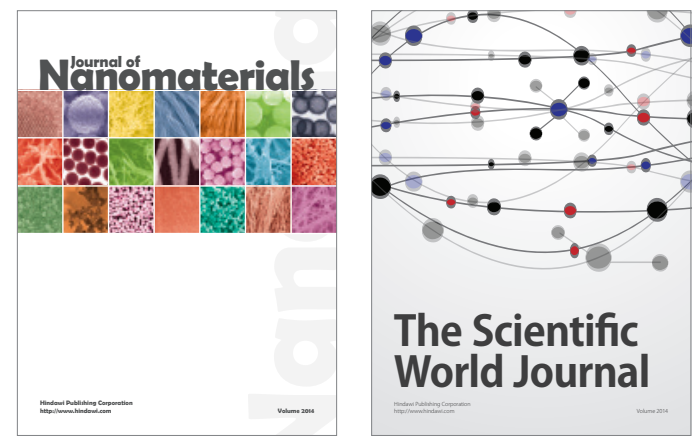

The Scientific World Journal
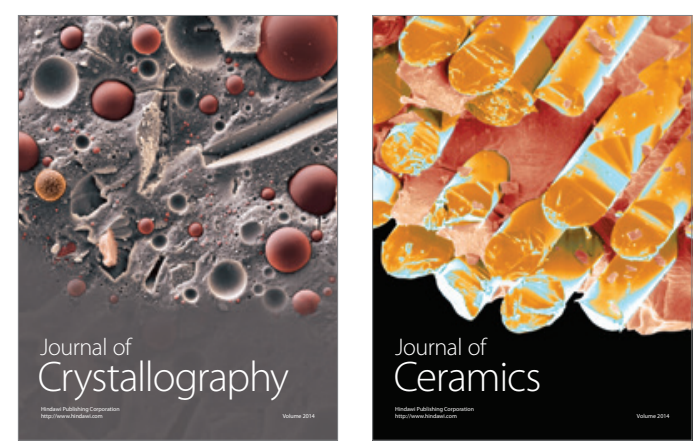
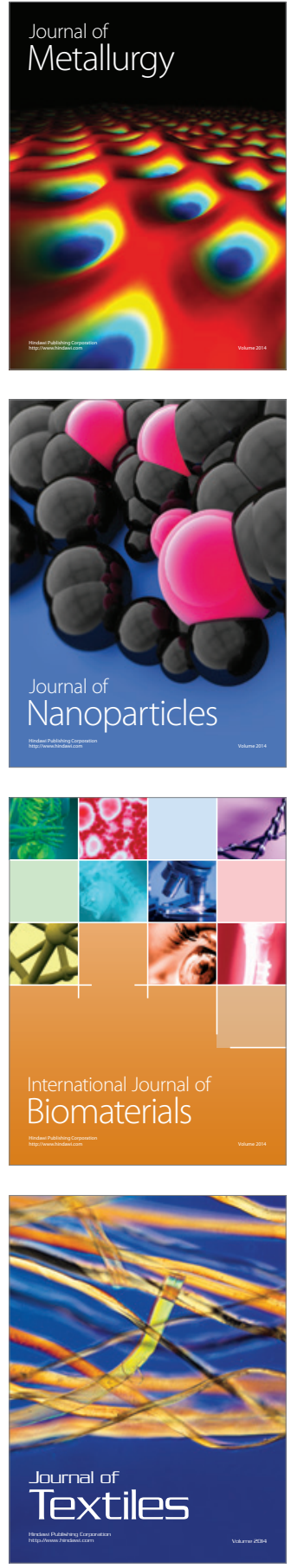